\title{
THE IMPACT OF TEXT DRIVING ON DRIVING SAFETY
}

\author{
Sanaz Motamedi ${ }^{1}$, Jyh-Hone Wang ${ }^{2}$ \\ ${ }^{1,2}$ Department of Mechanical, Industrial and System Engineering, University of Rhode Island, Kingston, RI 0288, USA
}

Received 4 February 2016; accepted 25 July 2016

\begin{abstract}
In an increasingly mobile era, the wide availability of technology for texting and the prevalence of hands-free form have introduced a new safety concern for drivers. To assess this concern, a questionnaire was first deployed online to gain an understanding of drivers' text driving experiences as well as their demographic information. The results from 232 people revealed that the majority of drivers are aware of the associated risks with texting while driving. However, more than one-fourth of them still frequently send or read text messages while driving. In addition to the questionnaire, through the use of a virtual-reality driving simulator, this study examined drivers' driving performance while they were engaged in some forms of text driving under different challenging traffic conditions. Through a blocked factorial experiment, drivers would either read a text message or respond to it with two levels of text complexity while using either hand-held or hands-free texting method. Their driving performance was assessed based on the number of driving violations observed in each scenario. Conclusions regarding the impacts of different forms of texting, text complexity, and response mode on drivers driving performance were drawn.
\end{abstract}

Keywords: hands-free text driving, hands-held text driving, driver distraction, driver safety.

\section{Introduction}

Distracted driving due to cell phone use has been identified as a major threat in driving, causing serious and sometimes fatal crashes. According to the National Safety Council (NSC), nearly $25 \%$ of all car crashes (1 out of 4) involved cell phone distraction. In 2011, cell phone use in motor vehicle crashes caused \$100B in damages (NSC, 2015). Due to the danger it poses to the public, cell phone use in driving has been banned in 37 states in the United State (Governors Highway Safety Association, 2015). Moreover, smartphones give people the opportunity to stay connected at all times not only by calling someone but also by texting and sending emails. These secondary tasks that people engaged while driving could cause serious safety risks. According to the National Safety Council, sixty percent of drivers read (but do not respond to) a text or e-mail while driving, and $25 \%$ of drivers read and respond to a text or e-mail while driving (NSC, 2015). As a result, 46 states have banned text driving (Insurance Institute for Highway Safety Highway Loss Data Institute, 2015). It is worth noting that hand-held texting is the main focus of these laws (NSC, 2010). Hands-free or voice control texting has gone legally unopposed as it is considered to be a safer texting alternative. However, there is some research indicated that handsfree form of texting is not harmless. This difference in perspectives is a testament to how widespread texting is, either hand-held

${ }^{1}$ Corresponding author: sanaz_motamedi@uri.edu 
or hands-free, and how it has become one of the today's greatest threats to motorist safety.

To address this modern life concern, text driving, a survey and a driving simulation study were conducted. The survey was given through SurveyMonkey to investigate which age groups text more frequently while driving, what the opinion of drivers' were about the effect of text driving, and gain a better understanding of drivers' form of text driving. After gathering the driver's demographics regarding their text driving experiences, a driving simulation experiment was conducted. A virtual-reality driving simulator experiment gauged the adverse effects of different forms of text driving under various roadway conditions and circumstances on individuals of different ages and genders. Subjects were asked to drive through various scenarios and read text messages, or read and respond to text messages in both hand-held and handsfree form. In addition to the form of the texting, two context complexity levels were considered. The context complexity levels affect the cognitive load of drivers. Moreover, during the experiment, subjects used their own personal smartphones and speech-to-text system to text in different forms and complexity levels while driving. The findings of this study will allow us to understand the impacts of text driving, whether it's hand-held or hands-free.

\section{Background}

Research shows that using a cell phone while driving and thus taking eyes off the road could lead to crashes (Stutts et al., 2001; Hedlund et al., 2006). Many legislators and drivers thought this risk was only associated with hand-held cell phone use while handsfree use would be much safer (Mayhew et al., 2013). Automobile manufacturers also claim that hands-free text-messaging systems reduce driver's distraction. For instance, Ford Motor Company examined driver performance while using the voice interface in Ford Motor Company's SYNC in a fixedbased driving simulator. They found that the voice interface minimized distraction compared to visual-manual interfaces (Shutko, 2009). Moreover, there are various naturalistic studies which indicated that auditory-vocal interfaces have driving performance advantages over visual-manual interfaces. For example, Dingus (2014) compared the effect of different secondary task on drivers' behavior and associated risk. Based on his research, it was clear that hand-held electronic interfaces were the most serious driving distraction due to their visual and manual interfaces. In addition to Dingus, other researchers have come to similar conclusions. They described the relative risks of specific secondary tasks while driving based on a naturalistic driving study. In contrast to hand-held texting or browsing tasks, listening and talking tasks were found not particularly risky (Dingus et al., 2011). In the crash analysis conducted by the Transportation Research Board, non-visual interfaces such as talking and calling were found safer if only such interfaces are indeed non-visual (Victor et al., 2013). Dozza et al. (2013) in his naturalistic study concluded that there was no difference between cell phone conversation and manipulation. Many researchers come to the conclusion that by keeping hands on the wheels and eyes on the roads, the risk associated with secondary tasks, such as text driving, has been removed.

On the other hand, some researchers found that by freeing the hands of drivers from devices cannot assure drivers' safety. According to the Governors Highway 
Safety Association, there are four types of distractions: Visual, Auditory, Manual, and Cognitive (William-Bergen et al., 2011). Hands-free or voice text driving involves all four types of distractions in various degrees. A research was conducted with both an onroad and a driving simulator experiment including cognitive, visual, and manual tasks with a voice prompt and non-voice prompt. It found there are less visual demands upon drivers with voice prompt tasks. Additionally, the difficulty of the tasks increased the intensity of mental workload (Xie et al., 2013). Interacting with a speech-to-text system was the most cognitively cumbersome activity compared to others such as listening to a radio, conversing with passengers, etc. (Strayer et al., 2013). The National Highway Traffic Safety Administration published guidelines for further investigations of this risky behavior. In details, this study involved a driving simulator and occlusion goggles under different text type, length, and ambient conditions. It examined the total eye-off-road time and total shutter open time in these different conditions. Understandably, the guidelines revealed that when the level of ambient complexity and length of text increased, the ratio of the total eye-off-road time and total shutter open time also increased. It is worth noting that this ratio slightly increased when reading a text rather than responding a text (Peng et al., 2014). Xie et al. (2013) indicated the drivers who were distracted by cell phones, did look at their environment but fail to see up to 50 percent of the information in their driving environment. Although vision is the most important sense for safe driving, drivers using hands-free phones have a tendency to "look at" but not "see" objects. Moreover, not only the way that drivers use cellphone while driving had impact on their behavior but also age and gender of drivers can be effective factors. According to Akaateba and Amoh-Gyimah 's study (2013), younger male had significantly more traffic violations regarding to cell phone use while driving due to overestimating of their driving skills.

Studies mentioned above measured some hands-free secondary tasks such as listening, calling and texting. The question here is how safe hands-free text driving can be, how the context complexity level of handsfree text driving affect drivers' behavior, and how much reading of a text message in driving is safer compared with responding to a text. It is the intention of this study to compare drivers' (balanced in age and gender) performances while they are text driving in two forms: hand-held and handsfree with two different levels of context complexity and two response modes: readonly and response-required. The impacts of these three factors on driver performance were assessed. Eight driving scenarios with multiple challenging road events and environmental conditions were developed to assess driver performance. Each driver was tested in all eight scenarios that varied by the three factors. The experiment results provided us with valuable information as to how the communication methods individuals employed in text driving could cause safety concerns while driving.

\section{Description of the Study}

To gain insight into drivers' performance associated with the different form of text driving in various challenging conditions, a survey and a driving simulation experiment were conducted. The survey investigated the texting habits and driving experience of drivers through SuveyMonkey on the Internet. The participants' demographic information such as age and gender were 
collected in order to establish experimental parameters such as blocking and sample sizing. Participants were asked to give a personal rating of how they believe texting affects their own driving, as well as whether they have ever used hands-free texting or not. The driving simulation experiment aimed to examine individual's driving performance with different forms of texting under various scenarios, including brake events, signs, and traffic rules. The designed experiment allowed a complete analysis of each participant's driving performance given various types of conditions as well as different forms of texting. A detailed description of both the survey and the driving simulation experiment is given below.

\subsection{Survey}

A survey (via SurveyMonkey) was conducted on smartphone users to inquire about their use of smartphones while driving. The online survey gave us the opportunity to recruit people anywhere in the country. It also eliminated the possibility of entering incorrect data from a pencil and paper survey. Using SurveyMonkey, the data downloaded directly to Excel which allowed us to do the further analysis. Participants completing the survey were asked to provide certain demographic information including age, gender, and detailed driving experience. Following that, five questions were asked about driver's experience in text driving such as frequency, form, and effect. They were also asked to provide a personal rating on how they felt texting while driving affected their driving. A total of 232 subjects, 119 females, 113 males, participated in the survey. Among them, 98 participants were in the $20+$ age group, 76 participants were in the $30+$ age group, 43 participants were in the $40+$ age group, 14 participants were in the $50+$ age group and one person in the $60+$ age group.

\subsection{Driving Simulation Experiment}

\subsubsection{Design of the Experiment}

The driving simulation experiment was designed to assess the effect of various forms of texting behaviors in driving. The factors investigated in the developed driving simulation experiment were categorized into two types: main factors and blocking factors (see Table 1). In particular, hand-held vs. hands-free texting was considered as the first main factor. Secondly, we also investigated whether responding to a text or simply reading a text had any influence on drivers' driving performance. Moreover, in order to see whether the context complexity of a text message had any significant impact upon performance, separate text conversations were created to generate a clear distinction between hard and easy texts. Following the survey results, we consider four age groups: $20+, 30+, 40+$ and $50+$, and two genders as blocking factors in the experiment. In total, three main factors and two blocking factors are measured.

Table 1

Driving Simulation Experiment Factors and Levels

\begin{tabular}{|l|l|l|}
\hline & Factors & Levels \\
\hline \multirow{3}{*}{ Main Factors } & Texting form & Hand-held, Hands-free \\
\cline { 2 - 3 } & Response mode & Read-only, Respond-required \\
\cline { 2 - 3 } & Text Complexity & Easy, Hard \\
\hline \multirow{2}{*}{ Blocking Factors } & Age & $20^{+}, 30^{+}, 40^{+}$, and $50^{+}$ \\
\cline { 2 - 3 } & Gender & Female, Male \\
\hline
\end{tabular}


A blocked factorial experiment design (Eq. (1)) with three main factors: the form of texting $(\mathrm{F})$, response mode $(\mathrm{R})$, and text complexity $(\mathrm{C})$ and two blocking factors: age $(A)$ and gender $(G)$ was employed in the study with the following model.

$y=\mu+\tau+\beta_{i}+\gamma_{k}+(\tau \beta)_{i j}+(\tau \gamma)_{i k}+(\tau \beta \gamma)_{i j k}+\delta_{l}+v_{m}+(\delta v)_{l m}+\varepsilon_{i j k l m}$

$\mu, \tau_{i}, \beta, \gamma_{k^{\prime}}(\tau \beta)_{i j},(\tau \gamma)_{i k}$ and $(\tau \beta \gamma)_{i j k}$ represent the effects of the main factors: $F, R, C$ and their two way and three way interactions, respectively. $\delta_{\nu} v_{m}$ and $(\delta v)_{l m}$ are the effects of blocking factors: A, G, and their interaction. $\varepsilon_{i j k l m}$ refers to the analysis error.

\subsubsection{Participants}

A total of 48 drivers balanced in age (four age groups considered) and gender took part in the experiment. The participants were recruited from the University of Rhode Island, the Rhode Island Division of Motor Vehicles (DMV), nearby Wal-Mart and shopping malls. All of the participants had their drivers' license for at least 2 years and drive approximately 12,000 miles annually. None of the participants had a record of cellphone violation while driving. All experiments were conducted in the Driving Simulation Lab at the University of Rhode Island.

\subsubsection{Driving Simulator}

A virtual-reality driving simulator in the lab was employed in the experiment. The simulator provides a high-fidelity real-world driving environment that can be customized for various applications (Wang and Song, 2011; Motamedi et al., 2015). The TranSim VS IV driving simulator, produced by the L3 Corporation, is a virtual-reality driving simulator which consists of a regular driving module and three channel plasma monitors in an immersive driving environment that combine the look and feel of a real vehicle. Participants interact with the simulator using a sedan's steering wheel and pedals that provide real-time feedback. A separate program called, "Scenario Builder" was used to create the desired conditions for scenarios. In this study, due to the consideration of two forms of texting, levels of the context complexity, and response modes, eight scenarios were developed and randomly assigned to each condition in order to avoid learning effects. The number of traffic violations occurred during each scenario was assessed. Fig. 1 gives a snapshot of the driving simulator employed in the experiment.

\subsubsection{Simulated Scenarios}

The participants engaged in eight scenarios including all combinations of the three main factors. In each scenario, the participants drove approximately one mile on the urban two-lane road. The participants were asked to keep their speed in the 25-35 mph range or they would be penalized in the speed maintenance or driving over speed limit categories. The challenging situations could include crash or near crash events, for instance, other drivers or pedestrians could emerge suddenly thus provoking collisions if not avoided. By demanding active action from the driver, we were able to obtain an assessment about each driver's performance. Moreover, these eight scenarios were not exactly similar in order to avoid the learning effect. These eight scenarios are similar in many ways, such as road environment, number of traffic lights, stop signs, left and right turns; however, they are different in objects such as people and cars used in the scenarios. Furthermore, the participants received a maximum of five texts while they 
were facing challenging traffic situations in each of the eight scenarios.

In the hand-held part of the experiment, participants held their own smartphones in their hand; and they received, read, and responded to text messages with varying levels of context complexity while driving. The participants were asked to use their personal smartphones to eliminate any variation caused by using an unfamiliar smartphone.

In the hands-free part, participants did not touch either their smartphones or any button. The texts were read aloud to them by a computerized voice which was created to mimic the interaction that would occur with an integrated Bluetooth hands-free audio system which is common in modern automobiles. Using simple voice commands, participants received and sent text messages vocally. The sequence of prompts simulates the hands-free audio systems in the modern automobiles. A computerized voice notified the driver: "You have received a new message. Do you want me to read it, yes or no?" The driver simply would say, "Yes" in order to vocally receive the text message. After listening to the text, the drivers were asked, "Do you want to respond?" Then the driver based on forms of the text message, read-only or respond-required, would answer.
The other factor investigated was reading or responding which added degrees of cognitive load which could adversely affect an individual's ability to drive. Two sets of text messages were developed regarding this factor (see Table 2). It is worth noting that at the beginning of the experiment, participants were informed that whether they would be required to read/listen to the text messages or to respond to them.

Additionally, the effect of the cognitive load of the text messages with different levels of the context complexity and forms was measured in this study. Two distinct sets of text messages were developed with cognitively "easy" and "hard" texts (see Table 2). The rationale behind our text development and selection lies in the idea of passive versus creative thought. By either presenting to or requesting information from a participant that incites or demands a thoughtful response as opposed to a simple regurgitation of fact, we can assuredly place a higher level of cognitive demand upon our subjects (Beede and Kass, 2006). For example, prompting the participant with a choice, perhaps siding on a controversial current event, they are forced to take a stance. In taking this stance, they put themselves through a rigor where they search their minds and decide on their values.

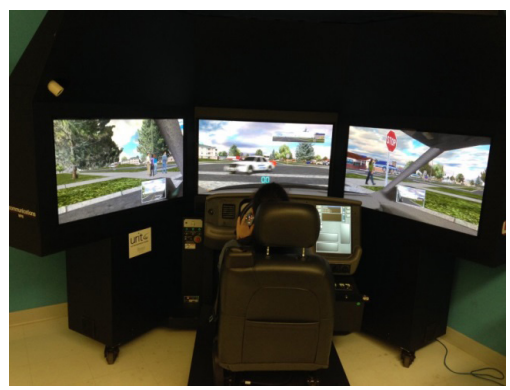

Fig. 1.

TranSim VS IV Driving Simulator Employed in the Experiment 
Table 2

Example of Text Messages

\begin{tabular}{|l|l|l|}
\hline Factor & Hard Level & Easy Level \\
\hline Read-only & $\begin{array}{l}\text { The budget for the curiosity rover that was } \\
\text { sent to mars is less than the worldwide military } \\
\text { expenditures made in only 13 hours. }\end{array}$ & $\begin{array}{l}\text { Hey, this is your assistant Steven. I have a new } \\
\text { phone number. I just wanted to make sure that } \\
\text { you could put me in your contacts" }\end{array}$ \\
\hline $\begin{array}{l}\text { Response- } \\
\text { required }\end{array}$ & $\begin{array}{l}\text { In March, Malaysia flight 370 disappeared. What } \\
\text { is the most surprising part of the Malaysian flight } \\
370 \text { mystery? }\end{array}$ & $\begin{array}{l}\text { Hey, how was your day? I was wondering what } \\
\text { time you are free. }\end{array}$ \\
\hline
\end{tabular}

\subsubsection{Conducting the Experiment}

An orientation video was administered to explain the experiment to the participants was given a 10 minute warm-up run, followed by the experiment. In total, a participant went through eight scenarios in random sequence. In addition to the random sequence of eight scenarios, all combinations of the three main factors were randomly chosen.

It is worth noting that at the beginning of each scenario, the participants were informed of the form of texting, hand-held or handsfree, and how they would need to respond to the text messages which they receive during the scenario. Then participants drove the 8 scenarios and did the different forms of text driving. They were allowed to take a break after each scenario.

\subsubsection{Measurement}

The participants' driving performance was recorded and monitored by two researchers and one video camera. The two researchers documented the driver's driving violations based on Table 3. The measured number of traffic violations that occurred within the eight scenarios was the response. Moreover, a video captured the entire test showing a direct shot of the driver and the screens in front of the driver. In the case of any disagreement between two researchers during the assessment, a video check process enabled the researchers to resolve the disagreement.

As mentioned above, the response was determined based on 10 categories as shown in Table 3. The numbers of violations were recorded for each of these categories with the exception of speed maintenance and visual focus which were measured with a Likert scale between 0 and 5 (the smaller, the better). The weights shown in Table 3 were obtained based on consultation with Division of Motor Vehicles driver examiners and traffic safety officials. Multiplying the number of recorded violation $\left(V_{i}\right)$ by its weight $\left(W_{i}\right)$ and subtracting the sum of all multiplied numbers from 100, an individual's score/response (the higher, the better) for each scenario was obtained (Eq. (2)). Therefore, it would be eight scores/ responses for each subject corresponding to eight scenarios (all combinations of the three main factors). Table 4 is one example of the recorded violation and the performance score/response.

$S_{\text {for each Scenario }}=100-\Sigma V_{i} \times W_{i}$ 
Table 3

Weights of Violations

\begin{tabular}{|l|l|l|l|l|l|}
\hline Violation & Driving Over Speed Limit & Following Distance & Improper Lane Position & Hard Braking & Collision \\
\hline Weight & 2 & 2 & 6 & 4 & 8 \\
\hline Violation & Hands off Wheel & Failure to Signal & Speed Maintenance & $\begin{array}{l}\text { Violating } \\
\text { Sign/Light }\end{array}$ & $\begin{array}{l}\text { Visual } \\
\text { Focus }\end{array}$ \\
\hline Weight & 2 & 1 & 1 & 4 & 2 \\
\hline
\end{tabular}

\section{Results and Discussions}

\subsection{Survey Results}

Two hundred and thirty-two people participated in the survey. Based on the answers obtained, $80 \%$ of the participants reported text driving for more than 3 years, $13 \%$ with 1 to 3 years of texting experience, and the rest with less than 1 year. Moreover, $20.3 \%$ of the participant's vehicles have an integrated hands-free feature for smartphones. Approximately $70 \%$ of them admitted using hand-held texting while driving, $17.2 \%$ have used both forms of texting, and the rest have used hands-free texting while driving. It is worth noting that $88.4 \%$ of the participants agreed that any form of texting while driving has negative or very adverse effects on their performance. However, $25.4 \%$ of them reported that they still often, frequently or very frequently do text driving. Fig. 2 and Fig. 3 illustrated the text driving frequency. Additionally, the frequency and effect of text driving was demonstrated in Fig. 4.

\subsection{Experiment Results}

Table 5 gives the mean driving performance at each level and condition. The results were analyzed using the ANOVA (with 95\% confidence level) procedure and the results are explained below (Table 6). Among all three main factors, the form of texting, handheld and hands-free, was significant with a p-value $<0.0001$. Moreover, as Fig. 5 shows, hands-free text driving caused significantly less distraction compared to hand-held text driving.

The other main factor that was significantly affecting drivers' performance was response mode $(p$-value $=0.024)$. Drivers had better performance in read-only than responserequired response mode (Fig. 5). It is worth noting that the text complexity factor appears to be marginally significant ( $\mathrm{p}$-value $=0.059$ ). In addition, there was only one two-way significant interaction between the response mode and texting form factors as shown in Fig. 6.

Table 4

Example of Recorded Violation

\begin{tabular}{|l|l|l|l|l|l|l|l|l|l|l|}
\hline $\begin{array}{l}\text { Violation } \\
\text { Score }\end{array}$ & $\begin{array}{l}\text { Over } \\
\text { Speed } \\
\text { Limit }\end{array}$ & $\begin{array}{l}\text { Following } \\
\text { Distance }\end{array}$ & $\begin{array}{l}\text { Improper } \\
\text { Lane } \\
\text { Position }\end{array}$ & $\begin{array}{l}\text { Hard } \\
\text { Braking }\end{array}$ & Collision & $\begin{array}{l}\text { Hands } \\
\text { off Wheel }\end{array}$ & $\begin{array}{l}\text { Failure } \\
\text { to Signal }\end{array}$ & $\begin{array}{l}\text { Speed } \\
\text { Maintenance }\end{array}$ & $\begin{array}{l}\text { Violating } \\
\text { Sign/ } \\
\text { Light }\end{array}$ & $\begin{array}{l}\text { Visual } \\
\text { Focus }\end{array}$ \\
\hline 81 & 1 & 1 & 1 & 0 & 0 & 1 & 1 & 0 & & 0 \\
\hline 75 & 2 & 1 & 1 & 1 & 1 & 0 & 1 & 0 & 0 & 3 \\
\hline 81 & 1 & 1 & 1 & 1 & 0 & 1 & 0 & 1 & & 0 \\
\hline 91 & 0 & 0 & 0 & 2 & 0 & 0 & 0 & 1 & 0 & 1 \\
\hline 83 & 0 & 1 & 0 & 1 & 0 & 1 & 0 & 3 & 0 & 0 \\
\hline 69 & 1 & 0 & 2 & 1 & 0 & 1 & 0 & 3 & 0 & 3 \\
\hline 83 & 1 & 1 & 0 & 1 & 0 & 0 & 1 & 2 & 1 & 1 \\
\hline 82 & 0 & 0 & 1 & 1 & 0 & 1 & 0 & 0 & 0 & 3 \\
\hline
\end{tabular}


According to the ANOVA results, among the blocking factors, age was significant with a p-value $<0.0001$. The second age group $(30+)$ drivers had better performance than other age groups (Fig. 6). Moreover, as you can see in Table 6, there is a significant interaction between age and gender (with a p-value $<0.0001$ ). Fig. 7 clearly illustrated that performance of drivers in the age group of $30+$ is better than other age groups regardless of the gender. It can also be seen that men had better performance than women in younger age groups $(20+$ and $30+$ ). However, men's performance was found worse than women's in older age groups such as $40+$ and $50+$.

According to the driver simulation experiment results, hands-free texting favorably impacted drivers' performance. In order to further investigate hands-free texting and its effect, we used ANOVA separately in all violation categories to identify those resulted in noticeably less distraction. The ANOVA results reported that hands-free texting could significantly help drivers maintain better visual focus on the road ( $p$-value $<0.001)$, speed maintenance ( $p$-value $<0.001)$, less hands off the wheel ( $p$-value $<0.001)$, better lane position $(p$-value $<0.001)$ and collusion $(p$-value $=0.018)$. With respect to other violations, driver's performance hands-free texting did not improve driver's performance.

\subsection{Discussions}

According to the survey result, although almost all of the participants agreed that any form of text driving has negative or very negative effects on their performance, nearly $25 \%$ of them reported that they still frequently or very frequently do text driving. This finding is supported by the National
Safety Council report about distracted drivers (NSC, 2010). Despite participants' stated belief in the dangers, they reported using cell phones while driving.

There are four types of distractions considered in text driving: visual, auditory, manual, and cognitive. Hands-free or voice texting while driving involves all four of these types of distractions in various degrees (William-Bergen et al., 2011). But the question is whether these distractions are unsafe? According to the driving simulation experiment results, hands-free text driving, compared to hand-held text driving, could lessen drivers' distraction especially in terms of visual and manual ability. The results obtained from this study clearly demonstrated that an auditory- vocal interface had advantages over visual-manual interfaces. This finding is consistently supported by many naturalistic studies (Dingus, 2014; Dingus et al., 2011; Victor et al., 2013; Dozza et al., 2013; WilliamBergen et al., 2011). Another promising finding is that the response mode of text driving mostly had a significant effect on performances could be blamed more on visual and manual distraction. This is also supported by previous studies (Strayer et al., 2013; Peng et al., 2014). Regarding the cognitive load effect of texting, the experiment results did show marginal significant differences between hard and easy levels of complexity. This finding agrees with the naturalistic studies which stated that drivers should be so deep in thought to increase the risk of crashes (Dingus, 2014; Dingus et al., 2011; Victor et al., 2013; Dozza et al., 2013; William-Bergen et al., 2011). It can be concluded that visual and manual distractions are key causes of crash or near crash situations while heavy cognitive load can worsen these distractions. 


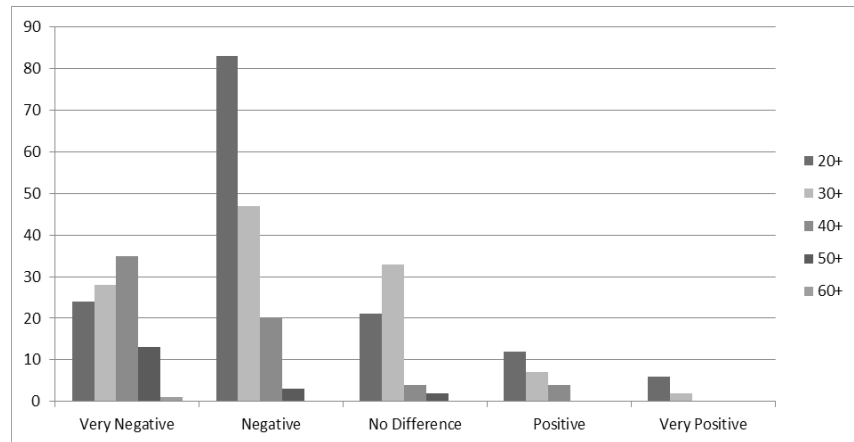

Fig. 2.

The Text Driving Effect on Driving Performance by Age Group

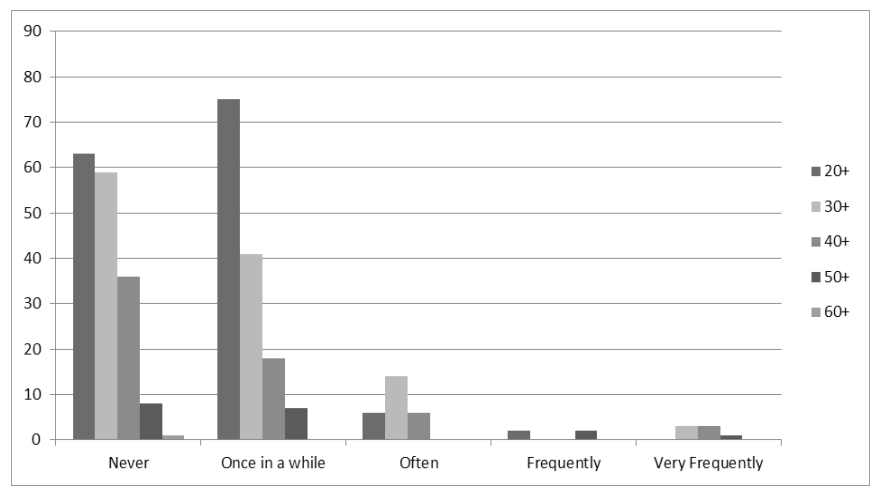

Fig. 3.

The Text Driving Frequency by Age Groups

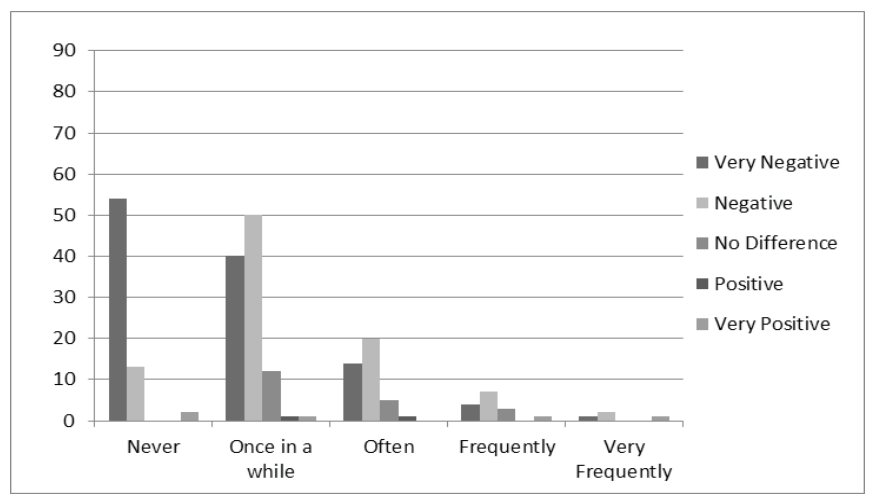

Fig. 4.

Frequency and Effect of Text Driving 
Table 5

Mean Responses at Various Level and Condition

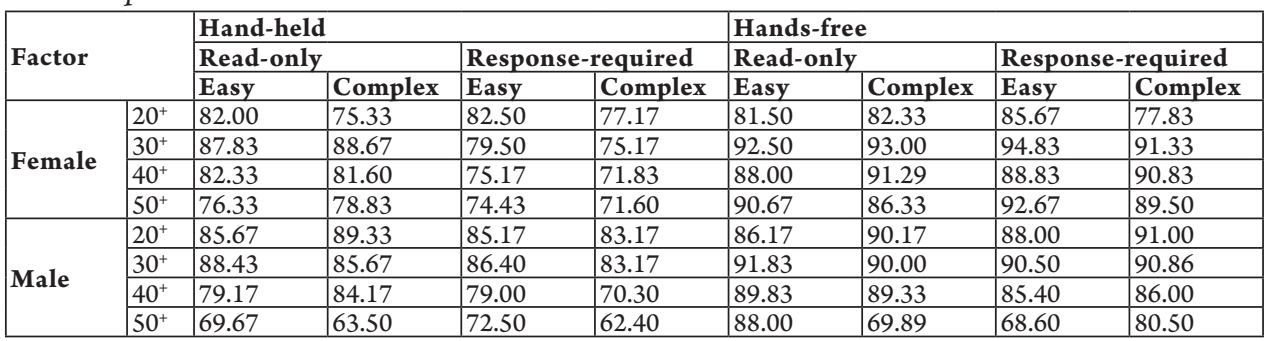

Table 6

ANOVA for the Full Model

\begin{tabular}{|l|l|l|l|l|l|}
\hline Source & DF & Adj SS & Adj MS & F & $\boldsymbol{p}$-value \\
\hline $\mathbf{F}$ & 1 & 6056.09 & 6056.09 & 67.76 & $<0.0001^{*}$ \\
\hline $\mathbf{R}$ & 1 & 462.00 & 462.00 & 5.17 & $0.024^{*}$ \\
\hline $\mathbf{C}$ & 1 & 320.92 & 320.92 & 3.59 & 0.059 \\
\hline $\mathbf{F}^{*} \mathbf{R}$ & 1 & 358.68 & 358.68 & 4.01 & $0.046^{*}$ \\
\hline $\mathbf{F}^{*} \mathbf{C}$ & 1 & 80.05 & 80.05 & 0.90 & 0.345 \\
\hline $\mathbf{R}^{*} \mathbf{C}$ & 1 & 44.22 & 44.22 & 0.49 & 0.482 \\
\hline $\mathbf{F}^{*} \mathbf{R}^{*} \mathbf{C}$ & 1 & 297.90 & 297.90 & 3.33 & 0.069 \\
\hline $\mathbf{A}$ & 3 & 5796.78 & 1932.26 & 21.62 & $<0.0001^{*}$ \\
\hline $\mathbf{G}$ & 1 & 119.58 & 119.58 & 1.34 & 0.248 \\
\hline $\mathbf{A}^{*} \mathbf{G}$ & 3 & 3699.3 & 1233.08 & 13.80 & $<0.0001^{*}$ \\
\hline Error & 369 & 32980 & 89.38 & & \\
\hline Lack-of-fit & 49 & 4666.2 & 95.23 & 1.08 & 0.347 \\
\hline Pure Error & 320 & 28314.6 & 88.48 & & \\
\hline Total & 383 & 49906.0 & & & \\
\hline
\end{tabular}

*Significant at $a=0.05$

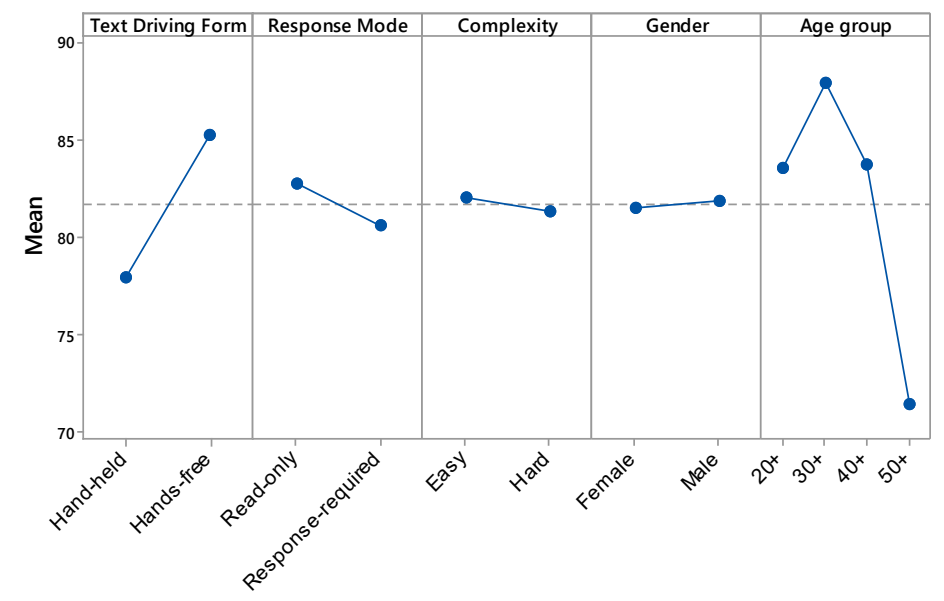

Fig. 5.

Main Effect Plots on Main Factors and Blocking Factors 

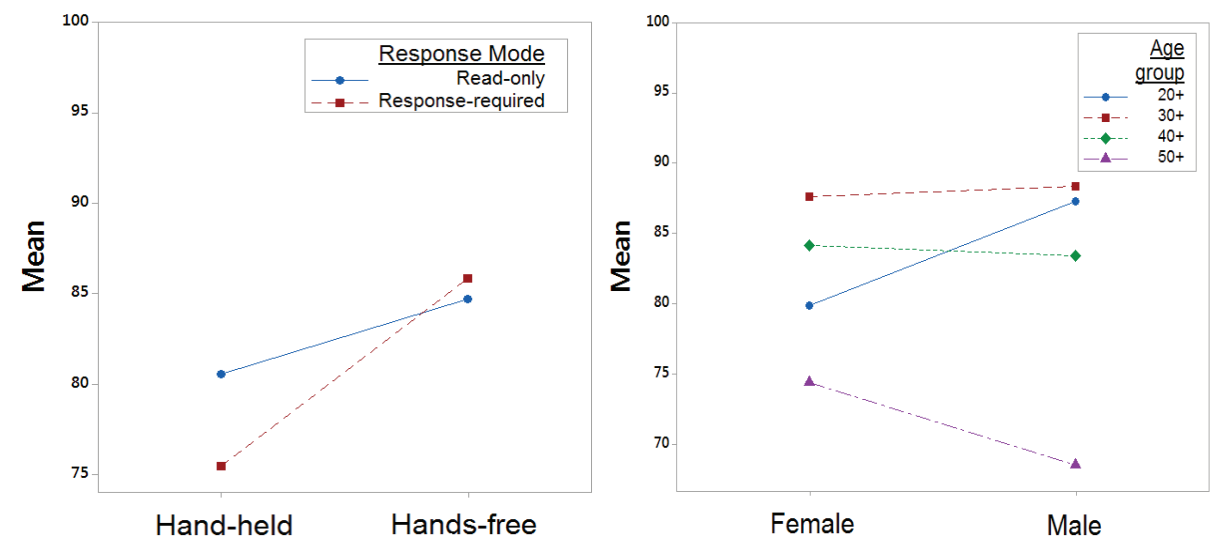

Fig. 6.

Interaction Plots Between Texting form and Response Mode, and Between Age and Gender

\section{Conclusion}

This study identified the impact of text driving in different forms, response modes, and complexity levels on driving performance. The online survey was conducted to gain a better understanding of the daily texting experiences and participants' text driving behaviors. The majority of drivers reported that they are aware of the many risks associated with text driving; however, approximately one-fourth of them reported that they still often do text driving. The driving simulation experiment examined the effect of two forms of text driving (hand-held and hands-free), two response mode (read-only and responserequired), and two levels of text complexity (hard and easy) on drivers' performance. As a result, hands-free texting and not responding to texts significantly improved drivers' performance in different challenging situations. The results gained from the study support the notion that reducing visual and manual distractions could improve driving safety. It also showed that the age of drivers affected the performance of their driving.
Male drivers in the $30^{+}$age group had the best performance while male drivers in the $50^{+}$age group had the worst performance. Gender does not appear to impact the driving performance.

Although this research utilized a high fidelity simulator with a high level of experimental control, replications of the study in real-life driving settings, such as naturalistic studies, are needed in order to ensure the validity of the findings. In future studies, other factors such as weather condition, traffic density, and visual conditions (day/night) will be addressed. Other forms of hands-free devices will be considered.

\section{Acknowledgements}

The authors would like to acknowledge The Rhode Island Department of Transportation; the University of Rhode Island Transportation Center; and the Mechanical, Industrial, and System Engineering Department of the University of Rhode Island for their support and guidance throughout this research project. 


\section{References}

Akaateba, M.A.; Amoh-Gyimah, R. 2013. Driver attitude towards traffic safety violations and risk taking behaviour in Kumasi: the gender and age dimension, International Journal for Traffic and Transport Engineering, 3(4): 479-494.

Beede, K.E.; Kass, S.J. 2006. Engrossed in conversation: The impact of cell phones on simulated driving performance, Accident Analysis \& Prevention, 38(2): 415-421.

Dingus, T.A. 2014. Estimates of prevalence and risk associated with inattention and distraction based upon in situ naturalistic data, Annals of Advances in Automotive Medicine, 58: 60-68.

Dingus, T.A.; Hanowski, R.J.; Klauer, S.G. 2011. Estimating crash risk, Ergonomics in Design: The Quarterly of Human Factors Applications, 19(4): 8-12.

Dozza, M.; Sayer, J.; Flannagan, C. 2013. Understanding driver self-regulating behavior: how does phone use influence vehicle control in real world?. In Proceedings of the 3 rd Conference of Driver Distraction and Inattention, Gothenbrug, 4-6 September, 2013.

Governors Highway Safety Association. 2015. Distracted Driving Laws. Available from Internet: <http://www. ghsa.org/html/stateinfo/laws/cellphone_laws.html>.

Hedlund,J.R.; Shults, A.; Compton, R. 2006. Graduated driver licensing and teenage driver research, Journal of Safety Research, 37(2): 107-121.

Insurance Institute for Highway Safety Highway Loss Data Institute. 2015. Distracted Driving. Available from Internet: <http://www.iihs.org/iihs/topics/laws/ cellphonelaws $/$ maptextingbans? topicName $=$ Distract ed\%20driving\#map >.

Mayhew, D.; Robertson, R.; Brown, S.; Vanlaar, W. 2013. Driver distraction and hands-free texting while driving. Traffic Injury Research Foundation, Ottawa, Ontario, Canada.
Motamedi, S.; Hasheminejad, M.; Choe, P. 2015. Driving Safety Considered User Interface of a Smartphone: An Experimental Comparison. In Cross-Cultural Design Applications in Mobile Interaction, Education, Health, Transport and Cultural Heritage, Springer International Publishing, 150-160.

National Safety Council. 2015. Distracted Driving: One Call Can Change Everything. Available from Internet: <http://www.nsc.org/learn/NSC-Initiatives/Pages/ distracted-driving.aspx? $\operatorname{var}=\mathrm{mnd}>$.

National Safety Council. 2010. Understanding the Distracted Brain: Why Driving While Using HandsFree Cell Phones Is Risky Behavior? Available from Internet: <https://www.fnal.gov/pub/traffic_safety/ files/NSC\%20White\%20Paper\%20-\%20Distracted\%20 Driving\%203-10.pdf $>$.

Peng, Y.; Boyle, L.N.; Lee, J.D. 2014. Reading, typing, and driving: How interactions with in-vehicle systems degrade driving performance, Transportation Research Part F: Traffic Psychology and Behaviour, 27: 182-191.

Shutko, J.; Mayer, K.; Laansoo, E.; Tijerina, L. 2009. Driver workload effects of cell phone, music player, and text messaging tasks with the Ford SYNC voice interface versus handheld visual-manual interfaces (No. 2009-01-0786). SAE Technical Paper.

Strayer, D.L.; Cooper, J.M.; Turrill, J.; Coleman, J.; Medeiros-Ward, N.; Biondi, F. 2013. Measuring cognitive distraction in the automobile. American Automobile Association Foundation for Traffic Safety, Washington, DC.

Stutts, J.C.; Reinfurt, D.W.; Staplin, L.; Rodgman, E.A. 2001. The Role of Driver Distraction in Traffic Crashes. [Online]. AAA Foundation for Traffic Safety Washington, DC, USA. Available from Internet: <http://www.safedriver.gr/data/84/distraction_aaa. pdf?ckattempt $=2>$. 
Victor, T.; Bärgman, J.; Dozza, M.; Rootzén, H. 2013. Safer Glances, Driver Inattention, and Crash Risk: An Investigation Using the SHRP 2 Naturalistic Driving Study. In Proceedings of the $3 r$ C Conference of Driver Distraction and Inattention, Gothenbrug, 4-6 September, 2013.

Wang, J.; Song, M. 2011. Assessing drivers' tailgating behavior and the effect of advisory signs in mitigating tailgating. In Proceedings of the Sixth International Driving Symposium on Human Factors in Driver Assessment, Training and Vehicle Design, Lake Tahoe, California, USA.
William-Bergen, B.; Hedlund, J.; Sprattler, K.; Ferguson, S.; Marti, C. 2011. Distracted driving: what research shows and what states can do. Governors Highway Safety Association, Washington, DC.

Xie, C.; Zhu, T.; Guo, C.; Zhang, Y. 2013. Measuring IVIS Impact to Driver by On-road Test and Simulator Experiment, Procedia-Social and Behavioral Sciences, 96: 1566-1577.

\section{ijtte 338}

